\title{
DETECTION OF SHIP VIBRATIONS AND ABSORPTION TECHNIQUES
}

\section{R. ELAVARASI}

Assistant Professor, Department of Electrical \& Electronics Engineering,

AMET Deemed to be University, Chennai, Tamil Nadu, India

\begin{abstract}
Ship Vibration is a major problem which occurs frequently in the on-board vessel. Excessive ship vibration may result in fatigue failure of local structural members, malfunctioning of machineries and equipments. Ship vibration includes machinery vibration and hull vibration. Hull vibration cannot be avoided whereas machinery vibration can be reduced. This paper introduces a system which will detect the vibration of the machinery, in case vibration of the machinery exceeds the ultimate value. The detecting system will trigger the alarm in the panel. Thus, as a response to the alarm the particular machinery is checked for fault and it is attended.

The root cause of the major failures in the machine is due to vibrations. It can't be noticed easily with the physical appearance of the machines. The consequence of this reason leads to major failures. For example: cracks in machine bed, cracks in the pipeline, wear and tear in bearings and gears.

To overcome this problem, a new system which detects the vibration and gives the alarm is proposed in this paper. This system includes a Vibrometer, Comparator, Amplifier and Alarm system.

Keywords: Vibrometer, Comparator, Amplifier \& Alarm System
\end{abstract}

Received: Jul 04, 2018; Accepted: Jul 25, 2018; Published: Aug 25, 2018; Paper Id.: IJMPERDOCT201813

\section{INTRODUCTION}

Effects of Vibration in Marine Machineries

The effects of vibration in marine machineries can be summarized as follows:

- In motors, vibration can accelerate bearing failure by causing indentations on bearing raceways of the ball or roller spacing.

- Formation of cracks in machine body.

- Metal fire may arise due to rubbing (vibration) of two overlapping surfaces.

- Loosening of foundation bolts and nuts due to heavy vibration.

- $\quad$ The machine loses stability.

- It is dangerous to human health also. 


\section{Block Diagram}

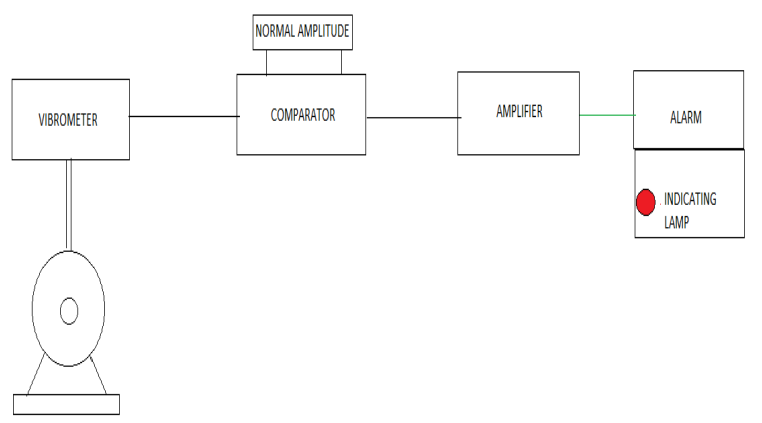

Figure 1

\section{Advantages}

The merits of the proposed system are given below:

- Makes engineer's job easier.

- Identifies the malfunctioning (heavy vibration) of the machine accurately.

- We can prevent the machinery from failure by the intimation given by the detecting system.

\section{SYSTEM OVERVIEW}

\section{Vibrometer}

The Vibrometer is an electronic impregnated device which measures the amplitude of the vibration of any vibrating body. This device sends the signal to the comparator.

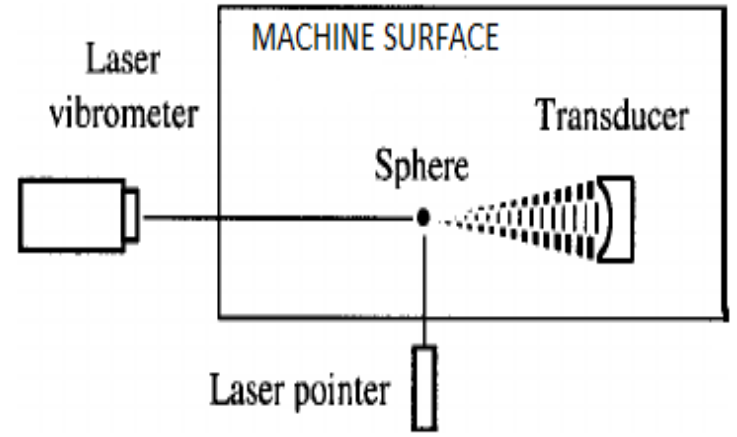

Figure 2

\section{Comparator}

The comparator gets the input signal and compares it with the reference signal and gives the output signal as the difference between the input and the reference signal. Succeeding it is given as an input to the amplifier. 


\section{Alarm and Lamp Circuit Diagram}

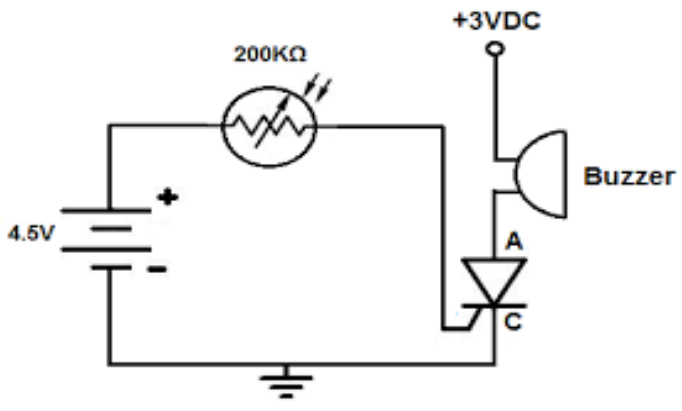

Figure 3

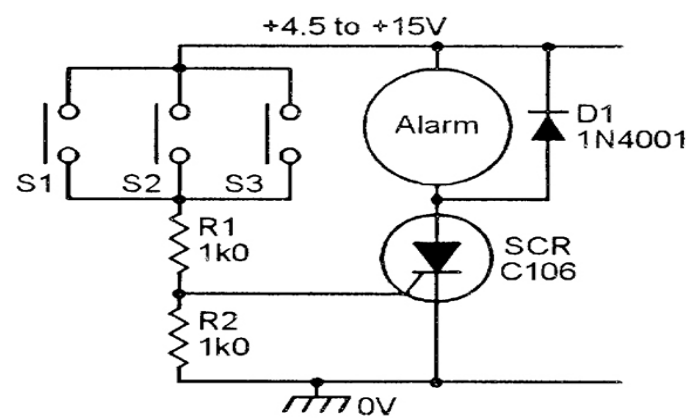

Figure 4

The alarm and lamp circuit is actuated by the amplified signal and the SCR is triggered by giving the gate pulse, as a result the alarm sounds and lamp glows.

\section{Amplifier}

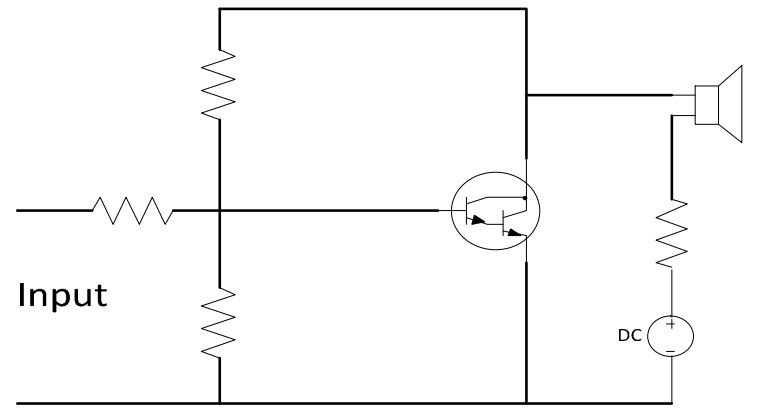

Figure 5

An operational amplifier is meant for increasing the magnitude of the input signal which may be a voltage or current. To improve the amplitude of the input signal, external power supply is given to the amplifier. The factor, namely gain, which is the ratio of output to input indicates the measure of amplification performed by the amplifier.

As discussed earlier, the output of the comparator is given as an input to the amplifier. The amplifier amplifies the difference signal which is obtained from the comparator and based on the level of the signal an alarm and indication lamp circuits are triggered. 


\section{VIBRATION DAMPING ARRANGEMENTS}

\section{Damping in Pipe Line}

Absorption of vibration by the metal hose is of flexible type. It consists of corrugated metal hose of the annular ring type. This metal hose also has braiding, side connecting pipe of short length and flanges. The metal hose is used for absorption of vibration during operation by the nature of its flexibility. The use of the braiding is to reinforce hose body against the pressure and thrust and compensate misalignment by changing its angle.

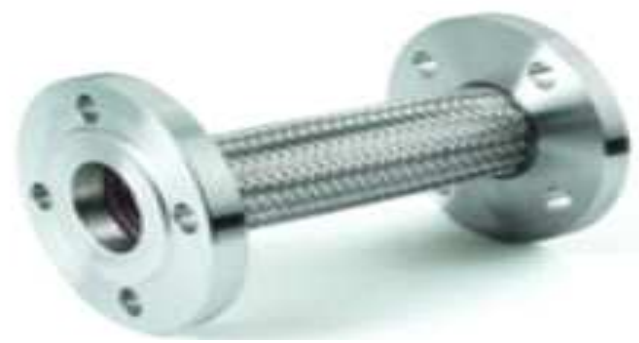

Figure 6

Pump and compressor are widely used in various projects. The unwanted vibrations and noise caused during ship operation leads to the reduction in life span of the equipment [4] and it is unhealthy to humanity [3]. For the reduction in ship vibration and noise caused, the FMH is favorable. The metal hoses must be fitted at the inlet part and outlet part of the pump and compressor for best quality of the project and better utility of equipment for long span. The use of flexible metal hose for vibration absorption can avoid the use of rubber in engineering applications and it also prevents from the burst of the equipment due to aging and failure of rubber fitting. The flexible metal hose is a good for engineering applications not only for absorption of vibrations and noise It also takes care of pipeline misalignment. Damping vibration sieve, the key lies in the generator is fixed on the damping.

In the ships, the built in shock absorber is provided with energy saving unit which gives the vibration absorption performance of the rubber shock absorber and a steel frame isolation. The isolation is sometimes needed between the above two in case of requirements. The steel frame and foundation is allowed for direct installations.

In case of the built in shock absorber with non- energy saving unit, isolation device must be included between the steel frame and foundation for vibration and noise absorption.

\section{Damping Arrangements in Large Conveyors}

The shock absorber can absorb the shocks thereby reducing the vibration to the ground. It is of different kinds, namely spring type shock absorber which is having high efficiency and second is of glass fiber type and the other one is of rubber type shock absorber which provides low efficiency compared to the above two. Due to aging, it may cause material failure and a burst of the equipment. Generally, rubber shock absorbers can be avoided in the ships.

The base isolation layer is developed at the bottom of the isolation trough in the width of $25 \sim 30 \mathrm{~mm}$. The foundation bottom is filled with cement, cinder, asphalt with a thickness of about $200 \mathrm{~mm}$, finally concrete is also poured on the isolation layer. 


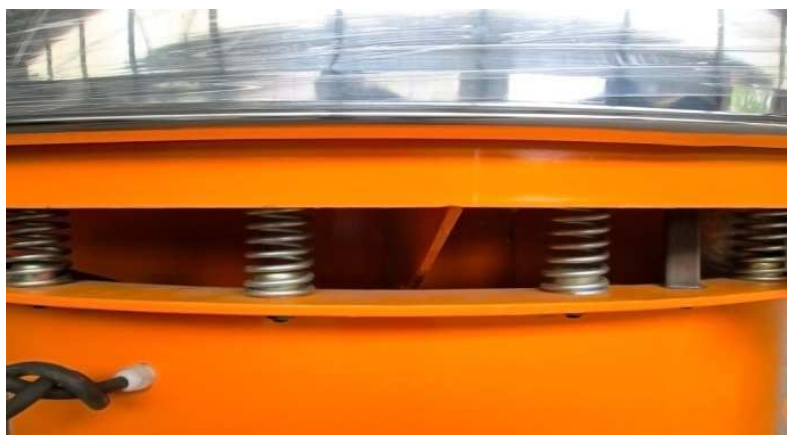

Figure 7

The Generator shall be anchored with the help of bolts of diameter M18 steel frame to the ground, so that movement of the generator can be prevented.

\section{Damping Big Structure}

Apart from shock absorber and generator arrangement in the ship, the cooling water tank must also be provided at the outer periphery for cooling purposes which must be placed at a distance of not less than $1.5 \mathrm{~m}$ with the room wall and also the height from the top of the unit room roof shall be not less than $1.5 \mathrm{~m}$. This is the minimum distance that must hold for ventilation and heat dissipation and maintenance unit lifting machine. The arrangement and distance of the base station from the ground are at least $150 \mathrm{~mm}$.

\section{ZDP Series Vibration Platform}

Vibration platform is mainly used for vibrating materials so that it can reduce the air gap within the materials. Generally, it uses with stock bin as a set. It is widely used in metallurgy, food industry, chemical industry, building materials industry, etc.

In the absorption process, the excitation force of vibration motor can be adjusted to make the materials in the platform to realize the ideal forms. Its effectiveness is stable; operation is reliable; noise is low. And it has a light weight, small volume and less power consumption. It is very simple to maintain and easy to install.

\section{Composition}

- Vibration platform is mainly composed of stands, vibration mechanism and vibration reduction mechanism. It was called a three-dimensional vibration platform because it can make the horizontal, vertical, up and down movement at the same time.

- The vibration mechanism of vibration platform is mainly composed of several sets of vibration motor and drive plates. In general, the number of vibration motor is even. And the main technical parameters are determined by the model of the three-dimensional vibration platform.

- The vibration reduction mechanism of vibration platform is mainly composed of damping, springg which is divided into rubber spring, composite spring, air spring, ect..

\section{WORKING}

This system is impregnated with electronic devices. The device is located near the machinery which need to be monitored. This device emits light on the machine surface and sense the vibration of the machinery. When this vibration 
exceeds the ultimate limit, the signal from comparator is high and it is amplified and the alarm and indicating lamp circuits are triggered $\mathrm{ON}$.

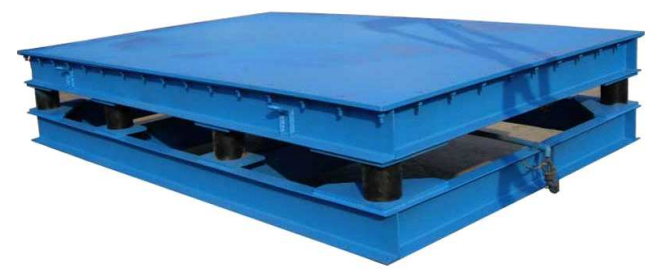

Figure 8

\section{FUTURE ENHANCEMENT}

The electronic control system can be implemented in this system by controlling the pressure of fluid in hydraulic and pneumatic suspension.

\section{CONCLUSIONS}

Thus the heavily vibrating machinery is identified from the control panel. As the response to the indication, the particular machine is checked for the fault and it is rectified.

\section{REFERENCES}

1. Lutzmann, Peter; Göhler, Benjamin; Hill, Chris A.; Putten, Frank van (2017). "Laser vibration sensing at Fraunhofer : review and applications". Optical Engineering.

2. Kilpatrick, James M.; Markov, Vladimir (2017). Tomasini, Enrico P, ed. "Eighth International Conference on Vibration Measurements by Laser Techniques: Advances and Applications". Eighth International Conference on Vibration.

3. Lloyd's Register Technical Papers; Ship vibration and noise: some topical aspects by J. S. Carlton and D. Vlašić

4. Cem Taşdemir and Özgür Demir, Noise and Vibration Analysis of a Tugboat, Conference Paper · December 2016.

5. Plunt J. (1980), "Methods for predicting noise level in ships", Report 80-07, Chalmers University of Technology.

6. SRZ, (2016), "Project Vectra $H A B(W B)$ noise and vibration measurement procedure and final report"

7. Kumar, A., \& Rao, K. S. Torsional Vibrations of Doubly-Symmetric Thin-Walled I-Beams Resting on Winkler-Pasternak Foundation Using Dynamic Matrix Method.

8. Marco Biot, Francesco De Lorenzo, Noise and vibration on board cruise ships, 2nd international conference on marine research and transportation, June 2007, Italy.

9. S. L. Gibbons, A. B. Lewis, P. Lord, Noise and vibration on board ship,, Journal of Sound and Vibration (1975) 43(2), 253261.

10. R. Elavarasi \& P. K. Senthil Kumar, Development of a MEMS Vibratory Gyroscope using High-Order Continuous time BandPass Sigma-Delta Modulator, Jour of Adv Research in Dynamical \& Control Systems.

11. G. Jegadeeswari, "Design and Implementation of THD Reduction for Cascaded Multilevel H-Bridge Inverter", Journal of Advanced Research in Dynamical and Control Systems (JARDCS).

12. R. Elavarasi \& P.K. Senthilkumar, "An FPGA based Regenerative Braking System of Electric Vehicle Driven by BLDC Motor”, Indian Journal of Science and Technology, Vol 7(S7), November 2014, pp.1-5. 